\title{
O uso turístico das comidas tradicionais: algumas reflexões a partir do Barreado, prato típico do litoral paranaense (Brasil)
}

\section{The touristic use of traditional foods: reflections from the example of Barreado, typical dish from coast Paraná State (Brazil)}

\author{
Maria Henriqueta Sperandio Garcia Gimenes (GIMENES, M. H. S. G.) *
}

\begin{abstract}
RESUMO - Este artigo tem como objetivo discutir o uso turístico das comidas tradicionais, tomando como exemplo o Barreado, prato típico do litoral paranaense. Baseando-se em documentos escritos e fontes orais, coletados durante a elaboração da tese de Doutorado em História intitulada "Cozinhando a tradição: festa, cultura e história no litoral paranaense", discute-se o turismo gastronômico, além de conceitos como prato típico e a questão da permanente convivência entre tradições e inovações no campo gastronômico contemporâneo.
\end{abstract}

Palavras-chave: Turismo Gastronômico; Comidas tradicionais; Barreado

ABSTRACT - This article aims at discussing the use of traditional foods for touristic purpose, taking the Barreado, a typical dish from the coast of Paraná State (Brazil) as example. Based on written and oral sources, collected during the preparation of a Doctoral thesis in History, entitled as 'Cooking the tradition: celebration, culture and history on the Paraná's coast', the gastronomic tourism as well as the concept of 'typical dish' and the permanent coexistence of tradition and innovation in the contemporary gastronomic field are discussed.

Key words: Gastronomic Tourism; Traditional foods; Barreado

\footnotetext{
* Bacharel em Turismo pela Universidade Federal do Paraná (UFPR). Mestre em Ciências Sociais e Doutora em História (UFPR). Professora do Curso de Turismo da UFPR. Endereço: Rua Dr. Faivre, 600, ap. 61 (Centro). CEP: 80060-140 - Curitiba - PR (Brasil). Telefones: (41) 3022-1779 (res.) e (41) 33605050 (com.).Email: mariahenriqueta@ufpr.br
} 


\section{INTRODUÇÃO}

O turismo gastronômico, aqui entendido como "uma vertente do turismo cultural no qual o deslocamento de visitantes se dá por motivos vinculados às práticas gastronômicas de uma determinada localidade” (GÂNDARA; GIMENES; MASCARENHAS, 2009, p. 181), já vem sendo desenvolvido com sucesso há várias décadas em países da Europa e da própria América do Sul. No Brasil, tal avanço tem sido lento, embora alguns estados como Bahia, Minas Gerais e Rio Grande do Sul realizem um bom trabalho de divulgação de seu patrimônio gastronômico.

Tal modalidade turística pode ser operacionalizada de diversas formas, por meio de rotas, circuitos e roteiros, bem como por estabelecimentos de alimentos e bebidas diferenciados ou ainda acontecimentos programados. Deve-se ressaltar, porém, que muitas vezes o atrativo tem como cerne as comidas e bebidas tradicionais. Estas iguarias, preparadas ao longo dos tempos e integrantes da cultura imaterial de suas respectivas comunidades, destacam-se em meio ao horizonte das comidas padronizadas que prevalece nos grandes centros urbanos, e muitas vezes se tornam uma possibilidade de conexão cultural ou com um estilo de vida que se deseja recuperar ou alcançar, potencializando a atratividade destas localidades.

Entretanto, a oferta destes pratos em escala comercial merece atenção, pois se por um lado amplia em muito a notoriedade da iguaria e democratiza seu consumo, por outro lado a expõe a uma maior sorte de inovações e adaptações, que podem descaracterizá-la. É neste sentido que a discussão sobre o uso turístico das comidas tradicionais ganha relevância e deve ser fomentada, unindo reflexões teóricas e análise de exemplos reais.

Neste sentido, tem-se como objetivo apresentar aqui algumas reflexões que contribuam para o debate do Turismo Gastronômico como estratégia de valorização e divulgação da gastronomia, como manifestação cultural e também como vetor de desenvolvimento socioeconômico e cultural de um destino. Tais considerações foram norteadas pelos dados coletados durante a realização da tese de doutoramento em História pela Universidade Federal do Paraná na linha de História da Alimentação, 
intitulada Cozinhando a tradição: festa, cultura e história no litoral paranaense ${ }^{1}$, que trata justamente da construção do Barreado (uma inusitada iguaria à base de carne bovina cozida exaustivamente com toucinho, cominho e louro até ganhar uma consistência desfiada), prato típico do litoral paranaense, e, por conseqüência, como atrativo e indutor do desenvolvimento turístico das cidades de Antonina, Morretes e Paranaguá. Durante tal pesquisa, além do intenso levantamento de fontes documentais, também foram realizadas 44 entrevistas com cozinheiras (os) tradicionais, cozinheiras (os) de restaurantes, proprietários e gerentes de restaurantes que servem o Barreado em seus cardápios, além de empresários e profissionais ligados à atividade turística nas localidades estudadas citadas acima.

\section{PENSANDO O TURISMO GASTRONÔMICO}

A relação entre o turismo e a gastronomia muitas vezes é restringida ao viés nutricional, focando a necessidade de estabelecimentos de alimentos e bebidas que atendam excursionistas e turistas durante a sua estadia. Todavia, a relação entre turismo e gastronomia (e, por conseqüência, os estabelecimentos a ela dedicados) é bem mais ampla e complexa.

Abandonando a perspectiva da mera necessidade fisiológica, é necessário pensar a alimentação como uma manifestação cultural e também uma forma de expressão humana, pois, como esclarecem a antropóloga Ana Maria Bonin e a socióloga Maria do Carmo Marcondes Brandão Rolim, "os hábitos alimentares se traduzem na forma de seleção, preparo e ingestão de alimentos, que não são o espelho, mas se constituem na

\footnotetext{
${ }^{1}$ A pesquisa que embasou a tese foi realizada por meio de revisão bibliográfica de temas como história da alimentação, história do litoral paranaense e alimentação como manifestação cultural, além de intenso levantamento documental de fontes primárias e secundárias (documentos dos órgãos municipais de cultura e turismo, documentos da Paraná Turismo e Secretaria de Turismo do Estado do Paraná, reportagens de jornais e revistas, folders e materiais publicitários dos municípios estudados e dos restaurantes que ofertam o Barreado). Como se desejava privilegiar o ponto de vista dos sujeitos envolvidos no processo de "turistificação" do Barreado, foram realizadas ainda quarenta e quatro entrevistas semi-estruturadas com cozinheiras tradicionais, cozinheiros e de restaurantes, proprietários e gerentes de restaurantes que servem o prato nas cidades de Antonina, Morretes e Paranaguá, bem como profissionais ligados à área de turismo, o que permitiu entender como se deu a construção da oferta comercial da iguaria na região litorânea e sua ligação com o desenvolvimento do turismo na área a partir da década de 1970 (GIMENES, 2008).
} 
própria imagem da sociedade" (BONIN e ROLIM, 1991, p. 76). Isso se dá porque tais escolhas não se fundam apenas em perspectivas objetivas (o que é comestível, o que se pode plantar, criar ou adquirir em determinada região), mas são determinadas também por aspectos subjetivos, que fazem parte de um sistema cultural mais amplo.

Assim, as decisões relacionadas à alimentação são suscetíveis às mudanças sociais, econômicas e tecnológicas, pois não são estabelecidas de forma isolada ou à revelia de um contexto maior, são construídas no mesmo bojo cultural que orienta as demais práticas e disposições do grupo social. Desta maneira, "mesmo cru e colhido diretamente da árvore, o fruto já é um alimento culturalizado, antes de qualquer preparação e pelo simples fato de ser tido como comestível” (GIARD, 1994, p. 232).

A partir desta premissa, a própria idéia de gosto alimentar deve ser expandida, pois ele já nasce permeado pela fusão do biológico com o cultural. O gosto alimentar então extrapola o domínio do aparelho sensorial humano e se aproxima da idéia defendida por Bourdieu (1983), para quem o gosto caracteriza uma propensão e uma aptidão à apropriação material e simbólica de uma determinada categoria de objetos ou práticas classificadas e classificadoras, constituindo a fórmula generativa de um estilo de vida. Este, por sua vez, corresponde a um conjunto unitário de preferências distintivas que exprimem, na lógica específica de cada um dos subespaços simbólicos, a mesma intenção expressiva que forma um princípio de unidade de estilo, um conjunto de gostos específicos. Neste sentido, integrantes de grupos sociais tendem a compartilhar certas aptidões de escolha (gosto) que terminam por conectá-los, tornandoos passíveis de serem reconhecidos como tal, inclusive no plano das decisões alimentares.

Desse modo, a própria utilização da gastronomia como elemento identitário remete à discussão de um estilo de vida. O churrasco gaúcho, por exemplo, encerra em seu saber-fazer vários outros elementos e rituais que respondem a uma conjuntura maior (a partilha do chimarrão, a figura do gaúcho) e reafirmam um estilo de vida vinculado a uma identidade regional. Da mesma forma, o preparo do acarajé pelas baianas nas ruas de Salvador não se resume ao uso de técnicas culinárias, mas representa e materializa uma série de elementos históricos e religiosos aos olhos do degustador.

Isso se torna possível porque o consumo alimentar muitas vezes se converte em uma modalidade de consumo simbólico, cuja essência reside no fato de que o que é 
consumido nunca é o objeto ou produto material, mas sim a relação (ou relações) que se estabelece com e através dele (BAUDRILLARD, 2000). A carga simbólica atrelada a um objeto faz com que ele transcenda seu valor utilitário e incorpore outras funções e, no caso específico da alimentação, faz com que a iguaria deixe de ser consumida por suas características físico-químicas e passe a ser degustada pelos valores simbólicos que lhe são atribuídos.

Seguindo esta lógica, o consumo de uma iguaria pode indicar status social (caviar Beluga), posicionamento ideológico (vegetarianismo), respeito a um código religioso (ausência de porco no cardápio de muçulmanos e judeus), pertencimento a um grupo (churrasco entre amigos) ou ainda preocupação com tendências dietéticas (redução de carboidratos e gorduras diante de discursos nutricionais e estéticos). Notase ainda que o preparo e o consumo de um prato podem propiciar um exercício identitário (quando a preparação e a degustação marcam o pertencimento a um grupo) ou uma conexão memorial (também relacionada à perspectiva identitária, diz respeito à capacidade de uma iguaria projetar lembranças e reavivar experiências).

É justamente a partir destas diferentes funções que podem ser atribuídas aos alimentos que o Turismo Gastronômico amplia suas possibilidades. Indispensável para a permanência do visitante, a gastronomia e os empreendimentos a ela relacionados podem ainda funcionar como agregadores de valor a outros serviços turísticos, tais como meios de hospedagem (por meio da estrutura de restaurantes, bares e serviço de quarto), meios de transporte (por meio do serviço de lanches e refeições, e até mesmo lautos jantares, no caso dos cruzeiros marítimos) e eventos (por meio do serviço de coffee-breaks, almoços, jantares e coquetéis).

A gastronomia como atrativo turístico pode ser operacionalizada de várias formas, por meio de rotas e roteiros turísticos (pode-se citar, dentre os exemplos brasileiros, os roteiros do vinho e do chocolate nas Serras Gaúchas/RS e as rotas da Cachaça no interior de Minas Gerais); restaurantes e estabelecimentos especializados (incluindo aí estabelecimentos produtores, como vinícolas, chocolaterias, alambiques e queijarias) e ainda acontecimentos programados (eventos gastronômicos focados em um prato típico, como é o caso da Festa Internacional do Porco no Rolete - Toledo/PR e da Festa Nacional do Carneiro no Buraco - Campo Mourão/PR, ou ainda em produtos 
agropecuários, como é o caso das Festas da Uva, espalhadas por todo o país, principalmente na região sul).

Deve-se mencionar ainda que os estabelecimentos de Alimentos e Bebidas, em especial bares, restaurantes e casas noturnas, muitas vezes se convertem em espaços de lazer e sociabilidade (GIMENES, 2004). Estes espaços, além de oferecerem comidas e bebidas dos mais diferentes tipos, orientadas para os mais diferentes nichos de demanda, terminam por complementar a oferta de entretenimento dos destinos, principalmente daqueles dedicados ao turismo de sol e praia, ou ainda com vocação para o segmento de eventos. Dependendo da característica do empreendimento, este pode por si só tornar-se um atrativo complementar ao patrimônio turístico local.

Contudo, quando se trata de atrativos de caráter gastronômico, é imprescindível comentar a importância das comidas e bebidas tradicionais e sua operacionalização em escala comercial. Como exemplo deste processo pode-se citar o Barreado, prato típico do litoral paranaense. De influência portuguesa, o prato se destaca por ser à base de carne de gado bovino (destoando do contexto culinário litorâneo dominado por peixes e frutos do mar) e por seu sabor inusitado, proporcionado pela união da carne de segunda com o toucinho, o cominho e o louro. Tais ingredientes são cozidos por horas seguidas, tradicionalmente em uma panela de barro, que é selada (o nome do prato vem da técnica de "barrear" a panela, vedando-a com uma mistura de farinha de mandioca, cinza de fogão e água e, em alguns casos, também com uma folha de bananeira) e só é aberta minutos antes do início da degustação. A iguaria é saboreada com farinha de mandioca (preferencialmente a artesanal) formando o famoso pirão, sendo acompanhada também por uma boa cachaça litorânea, preferencialmente a de banana (a cachaça é indicada porque dizem que beber água ou outro líquido "talha" o Barreado e também porque a aguardente "ajuda" a digestão).

O Barreado é degustado há centenas de anos, sendo intimamente ligado ao Fandango $^{2}$ e aos festejos carnavalescos do litoral. Apesar de ser historicamente

\footnotetext{
${ }^{2}$ O Fandango é uma manifestação cultural popular que reúne dança e música, praticado há centenas de anos no litoral sul de São Paulo e no litoral norte do Paraná, nas cidades de Cananéia, Iguape, Morretes, Paranaguá e Guaraqueçaba. Apesar de possuir regras estéticas definidas, há características específicas de cada localidade e variações das estruturas musicais e coreográficas. Em um baile ou em uma apresentação, várias modas ou marcas (como os fandangueiros chamam as músicas) são tocadas e dançadas. As danças são classificadas em valsadas ou batidas, dançadas em pares, com os homens batendo palmas e tamanqueando. Juntamente com o barulho dos tamancos têm-se a viola e a rabeca, geralmente feitas de caixeta e confeccionadas manualmente pelos próprios fandangueiros, além dos
} 
associado à Antonina, Guaraqueçaba, Guaratuba, Morretes e Paranaguá, apenas Antonina, Morretes e Paranaguá (que sustentam uma folclórica briga reivindicando a paternidade do prato) trabalham atualmente o prato em escala comercial, inclusive em termos turísticos. Um aspecto importante é que a tradição do preparo do Barreado continua viva nas residências e festas comunitárias, sendo peça integrante do cotidiano e da cultura local, mesmo tendo se expandido para as ruas e restaurantes das cidades, sempre tendo turistas e excursionistas como público-alvo.

Em Antonina, fundada em 1714 e atualmente com 17.581 habitantes (IBGE, 2008), dos nove restaurantes que oferecem atualmente o Barreado, cinco orientam seus serviços principalmente para a atividade turística e ao público que esta atrai para o município, somando juntos quatrocentos e trinta lugares. Considerando que nos períodos de maior procura (Carnaval, finais de semana, férias escolares e durante o Festival de Inverno da Universidade Federal do Paraná ${ }^{3}$ ) todos os estabelecimentos supracitados terminam por atender turistas e visitantes, a capacidade de atendimento da cidade para o Barreado sobe para setecentos e vinte lugares.

Paranaguá, por sua vez, apresenta uma realidade bastante diferenciada em relação aos demais municípios litorâneos. Fundada em 1648, conta com 133.559 habitantes (IBGE, 2008) e possui como alicerce econômico as atividades de exportação e importação realizadas pelo Porto Dom Pedro II, um dos principais portos do Brasil. A cidade é movimentada principalmente pelo fluxo de profissionais ligados às operações portuárias e os fluxos de lazer são motivados principalmente pela Ilha do Mel e pelas características históricas locais. A oferta do Barreado vem sendo divulgada e desenvolvida desde a década de 1990 de forma bastante associada ao Fandango, e alguns restaurantes incluem a iguaria em seus cardápios, mesmo que apenas como um item integrante de um extenso buffet. Deve-se mencionar que a cidade, gastronomicamente falando, é muito procurada pelos pescados e frutos do mar, que constituem a especialidade dos restaurantes locais.

instrumentos de percussão como o adufo (ou adufe) e o pandeiro. Comumente dançado durante o Entrudo (precursor do Carnaval), em festas familiares (de casamento, batismo, aniversários etc.) e também durante os mutirões (ou pixirões), ações conjuntas para plantio ou colheita da lavoura, que reunia vizinho e amigos e tinha no fandango uma espécie de comemoração pelo trabalho realizado.

3 O Festival de Inverno da Universidade Federal do Paraná (UFPR) é um programa de extensão permanente, criado em 1991 pela Pró-Reitoria de Extensão e Cultura e desenvolvido na cidade de Antonina, no Paraná. O festival agrega, além das atividades culturais, uma série de ações extensionistas de saúde, educação, inclusão social e geração de renda. 
Como reflexo dessa realidade, na cidade foram identificados sete estabelecimentos que servem a iguaria, sendo que o único que possui o Barreado como carro-chefe é a Casa do Barreado, um restaurante com capacidade para cem lugares que foi aberto em 1996 com uma proposta de resgate das tradições culinárias caiçaras. Considerando os outros estabelecimentos que também apontam nos turistas de lazer como seu público-alvo (Danúbio Azul e Restaurante Camboa), se têm mais quinhentos e oitenta lugares, contabilizado uma capacidade de seiscentos e oitenta pessoas servidas simultaneamente. Como já mencionado, os demais estabelecimentos servem o Barreado, mas praticamente não lhe dão destaque, oferecendo como mais uma opção, dentre outros pratos. Da mesma forma, não são direcionados para o turismo e não trabalham o potencial turístico do prato.

Se em Antonina há uma oferta do Barreado que põe a iguaria em relevo, mas que é prejudicada pelos pequenos fluxos de visitantes e em Paranaguá, com exceção de um único estabelecimento, a iguaria tem pouco destaque e é eclipsada pela oferta de outros pratos, Morretes, fundada em 1733 apresenta uma realidade bastante peculiar, de amplo destaque para o Barreado.

Com 16.998 habitantes (IBGE, 2008) e com uma economia baseada na agricultura e no turismo, o município possui dezoito estabelecimentos que servem regularmente o Barreado. Destes, quinze possuem como público-alvo o turista, e contabilizam um total de três mil, cento e vinte e seis lugares. Para se ter uma idéia da dimensão desta oferta, o Restaurante Madalozo, um dos pioneiros da comercialização do prato na cidade, dispõe - sozinho - de 690 lugares, mais a sala de espera, que pode abrigar mais 120 lugares em eventos. Considerando que nos períodos de maior procura (finais de semana e feriados, férias escolares) todos os restaurantes terminam por atender turistas, a capacidade total da cidade passa a ser de três mil, duzentos e oitenta e um lugares. Deve-se mencionar que a expansão de restaurantes e estabelecimentos comerciais similares vem sendo acompanhada pela expansão de meios de hospedagem e lojas de artesanato, e que o sucesso alcançado pelo turismo gastronômico, pautado justamente na oferta do Barreado, tem sido utilizado para divulgar e desenvolver outras potencialidades turísticas do município, como os passeios ecológicos (com o já tradicional bóia-cross) e a abertura de alambiques para visitação. 
No que se refere ao contexto de Morretes, deve-se destacar ainda a atuação da ARSIM, a Associação de Restaurantes e Similares de Morretes, que tem procurado melhorar as condições de produção e de atendimento dos restaurantes associados, além de divulgar o Barreado e o município como um todo. Dada a representatividade das empresas da área de alimentação para o turismo e, por conseqüência, para a economia do município, a ARSIM tem se preocupado com questões que transcendem à alimentação, como, por exemplo, a limpeza das ruas e a natureza do artesanato vendido durante as feiras e festas, procurando manter uma certa tipicidade daquilo que é oferecido. Outro aspecto que demonstra um alinhamento com a atividade turística e uma preocupação com a profissionalização é o fato de todos os restaurantes direcionados ao turismo serem citados em várias edições do Guia Quatro Rodas ${ }^{4}$ e serem associados à ABRASEL - Associação Brasileira de Bares e Restaurantes.

O crescimento da oferta do Barreado evidencia não apenas a boa aceitação da iguaria, mas o bom trabalho feito em termos de divulgação e atendimento de turistas e visitantes, que se deslocam até tais cidades para conhecer ou degustar mais uma vez o prato e terminam movimentando toda a cadeia produtiva do turismo local. Não obstante, é preciso lembrar que se trata da operacionalização de uma manifestação cultural, o que exige pensar criticamente o crescimento de tal oferta.

\section{ALGUMAS REFLEXÕES SOBRE O USO TURÍSTICO DE COMIDAS TRADICIONAIS}

Quando se trabalha com um prato como o Barreado, uma tradição que é operacionalizada e comercializada turisticamente, alguns pontos de reflexão se tornam evidentes: a necessidade de melhor delinear termos como gastronomia regional, prato típico e tradições gastronômicas; pensar as "funções" incorporadas por estes pratos no âmbito turístico; e ainda refletir sobre a permanente convivência entre tradições e inovações no campo gastronômico.

\footnotetext{
${ }^{4}$ O Guia Quatro Rodas é uma publicação renomada da Editora Abril para o segmento de viagens rodoviárias. Publicado anualmente, sugere roteiros e dá informações turísticas sobre localidades brasileiras, além de avaliar anonimamente meios de hospedagem e estabelecimentos de alimentação.
} 
Ao se falar de Turismo Gastronômico muito se fala em gastronomia regional e pratos típicos, embora muitas vezes estes termos sejam usados amplamente e de forma pouco criteriosa. No que tange à gastronomia regional, tem-se claro que, como em um primeiro momento (bem antes da abertura dos mercados internacionais e das facilidades de deslocamento de indivíduos e de produtos) a concepção de pratos e de outras iguarias estava limitada ao que se podia plantar e criar localmente, alguns sabores se tornaram marcantes, intimamente relacionados a regiões específicas. Da mesma forma, muitas técnicas culinárias nasceram como soluções para problemas práticos envolvendo a cocção e a transformação de alguns alimentos, iniciativas que terminaram por se cristalizar e caracterizar tais pratos (como é o caso da panela de barro vedada com uma mistura de água, farinha e cinza para conter a saída do vapor e preservar a umidade dos ingredientes durante seu cozimento, usada no preparo do Barreado).

Considerando que "os alimentos e os manjares se ordenaram em cada região segundo um código detalhado de valores, de regras e de símbolos, em torno do qual se organiza o modelo alimentar de uma área cultural num determinado período" (GIARD, 1994, p. 232), pode-se pensar a partir daí a formação da gastronomia regional, aqui compreendida como o conjunto de saberes-fazeres que englobam ingredientes, técnicas culinárias e receitas que são dispostas em um panorama relativamente coerente, delimitado geograficamente e passível de ser reconhecido como tal.

O termo prato típico é ainda mais utilizando no contexto da atividade turística. Dentro do contexto da gastronomia regional nota-se que algumas iguarias terminam por se destacar e, marcadas por determinadas especificidades (combinação de ingredientes, técnicas de preparo ou serviço, por exemplo) que sobrevivem ao passar dos tempos, são adaptadas e ressignificadas, mas mantêm uma essência identitária passível de ser reconhecida. Esses pratos, comumente denominados pratos típicos, se ligam à história e ao contexto cultural de um determinado grupo, constituindo uma tradição que se torna símbolo de sua identidade. Os pratos típicos (ou comidas típicas) são entendidos, portanto, como elementos integrantes da gastronomia regional que emergem deste conjunto mais amplo por inúmeras razões (praticidade, associação com outra prática cultural, associação a determinadas celebrações) e podem ser consumidos simbolicamente, desde que o comensal possua conteúdos capazes de permitir tal experiência. 
Abordando a questão dos pratos típicos, Maria Eunice Maciel (2004), discuteos a partir da idéia de cozinha emblemática. Para a autora, o emblema consiste em uma figura destinada a representar uma coletividade e faz parte de um discurso que visa o reconhecimento, na medida em que informa sobre o grupo do qual emerge e ao qual pertence. Fruto de relações sociais e objeto de negociações, embora possa parecer cristalizado, ele não o é, pois se relaciona com as vivências do conjunto de indivíduos e em conformidade com estas, podendo ser alterado, substituído ou abandonado. Continuando seu raciocínio, a antropóloga defende que as figuras emblemáticas regionais podem assim, ser vistas como marcas exteriores de distinção, sintetizadores de idéias, imagens e representações.

Os pratos típicos, desta forma, "constituem uma "cozinha emblemática", servindo para expressar identidades, sejam elas nacionais, regionais ou locais" (MACIEL, 2004, p. 220). Tem-se, assim, o surgimento de pratos que, mais do que representantes de uma cozinha regional terminam por ser tão associados a determinados grupos que passam também a representá-los. A relação imediata que se estabelece entre o churrasco e o gaúcho, entre o pão de queijo e o mineiro e entre o acarajé e o baiano são exemplos deste processo, fruto de um reconhecimento sustentado pelo grupo e que é também reconhecível pelos demais. Tal associação termina por criar uma marca para uma cidade, no sentido de caracterizá-la e também representá-la, podendo ser utilizada inclusive como uma forma de diferenciação de um destino turístico em relação aos seus concorrentes.

Sobre o termo tradição gastronômica, vale a pena refletir sobre o próprio termo tradição. Para o filósofo Gerd Bornheim, a tradição pode ser compreendida como o conjunto de valores dentro dos quais os indivíduos se estabelecem, não se tratando apenas das formas de conhecimento ou das opiniões, "mas também da totalidade do comportamento humano, que só se deixa elucidar a partir do conjunto de valores constitutivos de uma determinada sociedade" (BORNHEIM, 1997, p. 20). Desta forma, os indivíduos estariam instalados na tradição ao ponto de revelar-se muito difícil desembaraçar-se de seu domínio, pois esta também os constitui. No entanto, é importante observar que a tradição, mesmo estabelecendo uma sensação de constância e permanência, também sofre alterações compatíveis com as dinâmicas culturais dos grupos aos quais pertence. 
Assim, considera-se tradição gastronômica um saber-fazer transmitido entre gerações e cujos significados, dentro da própria lógica da dinâmica cultural, podem ser alterados ou adaptados, sem que sejam perdidas, no entanto, determinadas características e conteúdos que garantam seu reconhecimento. Deste modo, uma tradição gastronômica pode ser objeto de consumo de fato (consumo do alimento em si, de suas características físico-químicas e dos sabores gerados a partir da interação de seus ingredientes e técnicas de preparo) ou de consumo simbólico (quando for apreciada por conta de valores socialmente atribuídos ou das relações que podem ser experimentadas por meio deste prato), mas se mantém como tradição culinária por se tratar de uma iguaria que é degustada e preparada por gerações e que possui um vínculo com um contexto cultural maior. Tem-se claro ainda que essa tradição que se prepara e se compartilha e é constantemente ressignificada e recriada a partir da própria dinâmica cultural do grupo social, e, por demarcar identidades, pode permitir, inclusive, uma conexão memorial a partir de sua degustação.

Tal perspectiva se torna possível, pois como observa o antropólogo Sidney Mintz (2001, p. 32), os hábitos alimentares "podem mudar inteiramente quando crescemos, mas a memória e o peso do primeiro aprendizado alimentar e algumas das formas sociais aprendidas através dele permanecem, talvez para sempre, em nossa consciência”. O conceito de alimento-memória cunhado por Santos (2004) diz respeito às iguarias que, ao serem degustadas, permitem uma experiência nostálgica e uma conexão com conteúdos simbólicos que podem estar associados tanto à memória individual (lembranças pessoais da infância) quanto à memória coletiva ${ }^{5}$ (lembranças de situações experimentadas - ou "herdadas" no seio dos grupos sociais), exercitando a chamada memória gustativa.

Neste sentido, afirma-se que a intenção de quem prepara e de quem degusta, principalmente deste último - deve-se ressaltar - é imperiosa para a compreensão do conceito de alimento-memória, pois este movimento de "religamento", de conexão memorial que se dá a partir da ingestão de uma iguaria só é possível tendo como base

\footnotetext{
${ }^{5}$ A idéia da memória coletiva mencionada aqui é baseada nas contribuições de Maurice Halbwachs (1990), estudioso dedicado ao entendimento dos chamados "quadros sociais da memória" e defensor do pressuposto de que as lembranças permanecem coletivas justamente porque o homem é membro de vários grupos (comunidades afetivas) e suas lembranças dependem da relação que este indivíduo estabelece com estes diferentes grupos, pois só se é capaz de algo a que ainda se está de alguma forma vinculado. Neste contexto, a memória se caracteriza também como um fenômeno social construído coletivamente e submetido a flutuações, transformações e mudanças constantes.
} 
algo ao qual um dia se esteve efetivamente ligado de forma emocional, seja por meio de uma vivência pessoal ou coletiva.

Retomando o exemplo do Barreado, tem-se claro que ele consiste em uma tradição gastronômica. Entretanto, pode ou não desempenhar a função de alimentomemória, pois para aqueles que o degustavam na infância ou na juventude, ou que tinham no prato o símbolo de eventos especiais, saboreá-lo na casa dos pais ou até mesmo em um restaurante pode sim se caracterizá-lo como tal. Contudo, para aqueles que não possuem nenhuma ligação com a iguaria e vão degustá-la por curiosidade na casa de amigos ou em restaurantes, ou ainda a comem com freqüência por gostarem de seu sabor, a idéia do alimento-memória não se concretiza. Assim, pode-se afirmar que, para que uma tradição gastronômica se caracterize como um alimento-memória é imprescindível que o degustador possua os referenciais memoriais e culturais adequados.

Considerando as múltiplas motivações e intenções que envolvem a degustação do Barreado (e não apenas este prato), parece adequado introduzir aqui outro conceito: o de alimento-signo. O alimento-signo é aquele que encerra uma série de significados, um conjunto de valorações simbólicas que lhe são atribuídas e que permitem que sua degustação transcenda a experiência sensorial e se caracterize também como uma experiência cultural e emocional. Assim, trata-se de um conceito mais amplo, que abrange as próprias idéias de tradição culinária e de alimento-memória, sem convertêlas, no entanto, em sinônimos, mas que também permite pensar outras formas de consumo simbólico destes pratos e iguarias que não são contempladas pelos conceitos anteriormente citados.

Dentro deste conceito podem-se incluir iguarias que são trabalhadas turisticamente, mas que não necessariamente se caracterizam como tradições culinárias por serem criações recentes ou ainda estarem por se construir como tradição. No entanto, a degustação de tais elaborações pode oferecer, além da experiência sensorial (vinculada aos sabores presentes naquilo que é degustado), uma experiência cultural (no sentido de uma aproximação com a realidade visitada e com os hábitos e costumes do grupo que o prepara). Tomando como exemplo o próprio Barreado, uma tradição culinária, pode ser degustado como um alimento-memória por um determinado grupo, e, na mesa ao lado, ser consumido como um atrativo turístico, um símbolo litorâneo que 
não se pode deixar de saborear quando se desloca para Morretes, por exemplo. Em ambos os casos, o Barreado é um alimento-signo, pois as motivações e experiências envolvidas transcendem à questão sensorial e aglutinam valores simbólicos (de nostalgia, de contato com a realidade visitada) à sua degustação. Caso o Barreado seja degustado apenas como mais uma opção de carne, sem que haja uma valoração simbólica, se concretizará somente o consumo de fato.

Aumentando a complexidade e o escopo da análise do uso turístico das comidas tradicionais, é importante observar que as mesmas convivem com inúmeras inovações. No caso do Barreado, além dos temperos que são adicionados por conta do gosto de cada cozinheiro (como manjerona, salsinha e cebolinha e até mesmo o polêmico tomate ${ }^{6}$ ), algumas alterações foram identificadas, como a substituição do toucinho cru (ou branco) pelo bacon (toucinho defumado). Foram detectadas também inovações de ordem tecnológica, como a substituição do fogão à lenha pelo fogão à gás, da tradicional panela de barro pela de alumínio, a substituição no lacre da folha de parreira por plástico filme e até mesmo o hábito de produzir o prato em grande quantidade (devido a demora em seu preparo) e depois congelá-lo para servi-lo nos dias posteriores.

Em alguns restaurantes, é montado um buffet com panelas de barro para que o cliente possa se servir. Em outros, o Barreado e seus acompanhamentos (além da banana e da farinha muitas vezes é servido arroz branco, mas também existe a opção de Barreado com Frutos do Mar, que é disseminada principalmente nos restaurantes de Morretes) em cumbucas de barro ou cerâmica, tentando reproduzir a imagem tão tradicional da panela de barro (mesmo que a panela de alumínio é que tenha sido usada no preparo). Reinterpretações da receita, como o Penne ao Molho de Barreado, o Bolinho de Barreado, a Banana recheada de Barreado e a Pizza de Barreado também foram observadas, além das receitas de Barreado Light.

A partir da análise da comercialização do Barreado, verificou-se que, na realidade cotidiana, a permeabilidade entre as tradições e as inovações no âmbito

\footnotetext{
${ }^{6} \mathrm{~A}$ introdução ou não do tomate na receita do Barreado é motivo de polêmica inflamada entre os moradores de Antonina, Morretes e Paranaguá. Para a grande maioria, o tomate nunca fez parte da receita, sendo inclusive responsável pelo "azedamento" do prato. Sua utilização, segundo estes, é feita por aqueles que desrespeitam a regra de cozimento exaustivo, e que o adicionam para conferir ao caldo a cor que naturalmente seria conseguida durante o período longo que a panela passasse ao fogo. Aqueles que o defendem, dizem que o tomate não azeda o prato, e muito menos altera seu sabor, apenas confere uma cor mais bonita e mais atrativa aos olhos e convidativa ao estômago.
} 
alimentar é bastante grande, e que de forma constante tradições vão sendo criadas ou ressignificadas, seja pela substituição de ingredientes que não estão mais disponíveis (por questão de deslocamento geográfico, altos preços ou até mesmo problemas sanitários e dietéticos) ou pela substituição de técnicas, equipamentos e utensílios que facilitam os processos de preparo. Tais adaptações foram detectadas também no uso doméstico, mas é no âmbito comercial que se mostraram mais disseminadas, justificadas pelos entrevistados pela necessidade de otimização da produção em termos de rapidez, segurança e melhoria da relação custo versus benefício.

Como ressaltam Bonin e Rolim (1991) padrões ditos "tradicionais" e "modernos" convivem em uma mesma sociedade, orquestrados pela dinâmica cultural que também engloba os hábitos alimentares. Assim, verifica-se que nas sociedades urbano-industriais "as escolhas alimentares são agora individuais; a produção de alimentos foi incorporada à troca de mercadorias, e os alimentos em geral se tornaram profanos" (BONIN; ROLIM, 1991, p. 78), o que não impede, entretanto, a permanência de formas tradicionais de comensalidade, como as festas marcadas socialmente (Natal, casamentos etc.). Obviamente o aprimoramento tecnológico da cozinha (mesmo a doméstica), a preocupação com os critérios de saúde e nutrição (a vigília contra a gordura e alimentos muito calóricos, como é o caso do Barreado) e a necessidade de otimização do preparo de alimentos, reduzindo o tempo de espera, a possibilidade de contaminação e aumentando o número de refeições servidas fazem parte do quadro mais amplo das sociedades modernas. A questão reside justamente em que medida tais inovações podem ser incorporadas sem que as comidas tradicionais sejam descaracterizadas e sem que o Turismo Gastronômico perca a matéria-prima a partir da qual se desenvolve.

\section{CONSIDERAÇÕES FINAIS}

A partir das abordagens contidas neste trabalho, verifica-se que o Turismo Gastronômico pode trazer uma série de benefícios para todos os envolvidos. No que tange ao destino que o desenvolve, pode incrementar sua oferta turística, diferenciá-lo em relação aos seus concorrentes diretos e indiretos e ainda complementar a oferta de 
lazer e de entretenimento, gerando empregos diretos e também aumentando a atratividade de uma localidade, incentivando, por conseqüência, o aumento da permanência dos visitantes.

Ao desenvolver o enfoque turístico das comidas tradicionais, verifica-se ainda a possibilidade de valorização cultural a partir da recuperação e divulgação das receitas das tradições a ela relacionadas; o incentivo aos produtores agrícolas e de criações de animais (no sentido de que a maioria dos ingredientes tende a ser originária da região) e também aos artesãos cujo ofício se relaciona com a gastronomia. Do ponto de vista do turista, além da experiência sensorial e de saciação fisiológica, tem-se a possibilidade de um consumo simbólico na medida em que, ao degustar a iguaria, o indivíduo consome também um pouco do contexto cultural que está visitando, que pode permitir inclusive uma conexão nostálgica.

Entretanto, justamente por tratar-se do desenvolvimento da atividade turística pautado em uma manifestação cultural se torna necessária uma reflexão mais ampla, que ultrapasse as questões operacionais vinculadas à comercialização de alimentos e bebidas. Neste sentido, procurou-se aqui levantar algumas discussões que se tornaram evidentes durante o estudo do Barreado e que possam ser pertinentes a outros estudos de pratos típicos que se consolidaram como atrativos turísticos. Espera-se assim contribuir para o debate acadêmico do Turismo Gastronômico e para o desenvolvimento deste segmento tão rico em possibilidades.

\section{REFERÊNCIAS}

BAUDRILLARD, J. O sistema dos objetos. São Paulo: Perspectiva, 2000.

BONIN, A.; ROLIM, M. C. M. B. Hábitos alimentares: tradição e inovação. Boletim de Antropologia. Curitiba, v. 4, n. 1, p. 75-90, jun. 1991.

BORNHEIM, G. A. O conceito de tradição. In: BORNHEIM, G. A. et al. Tradição/Contradição. 2. ed. Rio de Janeiro: Jorge Zahar/Funarte, 1997.

BOURDIEU, P. Gostos de classe e estilos de vida. In: ORTIZ, R. Sociologia. São Paulo: Ática, 1983. 
GÂNDARA, J. M. G.; GIMENES, M. H. S. G.; MASCARENHAS, R. G. Reflexões sobre o Turismo Gastronômico na perspectiva da sociedade dos sonhos. In: PANOSSO NETTO, A.; ANSARAH, M. G. (Org.). Segmentação do mercado turístico - estudos, produtos e perspectivas. Barueri: Manole, 2009.

GIARD, L. Cozinhar. In: CERTEAU, M. de. A invenção do cotidiano - morar, cozinhar. Petrópolis, RJ: Vozes, 1996, p. 211-332.

GIMENES, M. H. S. G. Bares e casas noturnas: um estudo exploratório sobre consumo e sociabilidade. In: Turismo em análise, São Paulo, v. 15, n. 1, p. 73-88, 2004.

. Cozinhando a tradição: festa, cultura e história no litoral paranaense. Tese (Doutorado em História) - Setor de Ciências Humanas, Letras e Artes, Universidade Federal do Paraná, Curitiba, 2008.

HALBWACHS, M. A memória coletiva. 2. ed. São Paulo: Vértice, 1990.

IBGE. Perfil dos municípios brasileiros. Disponível em: <http://www.ibge.gov.br/home/estatistica/economia/perfilmunic/default.shtm>. Acesso em: $20 / 10 / 2008$.

MACIEL, M. E. Uma cozinha à brasileira. In: Estudos Históricos. Rio de Janeiro, n. 33, p. 25-39, jan.-jun. 2004.

MINTZ, S. W. Comida e antropologia - uma breve revisão. Revista brasileira de ciências sociais, Rio de Janeiro, v. 16, n. 47, out. 2001.

SANTOS, C. R. A. dos. A alimentação e seu lugar na História - os tempos da memória gustativa. Campinas, ANPUH Nacional, 2004.

Recebido em: 10/02/2009

Aprovado em: 10/03/2009 